\title{
A Computational Fluid Dynamics Study of the Swirl Generation Analysis in Four-stroke Direct Injection Engine
}

Chun Xu C and Muk Choa $\mathrm{H}^{*}$

Division of Mechanical and Automotive Engineering, Kongju National University 275, Budae-dong, Cheonan-si, Chungcheongnam-Do 331-717, South Korea

\begin{abstract}
In this study, the Computational Fluid Dynamics (CFD) simulation to investigate the effect of two piston crowns to the field inside the combustion chamber of a four-stroke direct injection automotive engine when at the motoring condition. The field flow into the chamber for air-fuel mixing to obtain the better swirl ratio, engine combustion, performance and efficiency when the swirl is appeared. So this analysis is important on this study of the effect of the piston shapes to the fluid flow and the air into the cylinder, The behaviors of fluid flow occurred inside combustion chamber is represented by two parameters which influences the air streams to the cylinder during intake stroke and improves the swirl of the air-fuel to produce better air-fuel mixing during the compression stroke. To investigate the effect of air-fuel swirl when change the intake valves conditions and the piston crown shapes. The numerical simulation analysis can be showed the swirl ratio when the air-fuel into the combustion chamber that the condition of the intake valves and the shapes of the piston crown in the combustion chamber by use the Computational Fluid Dynamics (CFD) mode.
\end{abstract}

Keywords: Computational Fluid Dynamics (CFD); Piston crown shape; Swirl ratio; Fluid flow; Air-fuel mixture; Intake valve

\section{Introduction}

The in-cylinder flows of Internal Combustion Engine (ICE) that the flow structure generated by intake flows is related closely to the design and performance of the ICEs. One of the most important factors for stabilizing the ignition process and fast propagation of flame is the production of high turbulence intensity. In general, the swirls and tumble flows which two types of vortices are utilized in order to generate and preserve the turbulence flows efficiency. The two types of the vortices are organized rotations in the horizontal and vertical plane of the engine cylinder respectively. They improved the engine performance by the mixing of fuel and induced air [1]. It is very important for the development of the ICE with high compression ratio to realize higher turbulence intensity and lean burn combustion.

On the other hand, we can add the shrouds to the intake valves to produce airflow swirl. Consider the two sets of intake valves' structures that the first set of conventional valves and the second set of valves which can be set up back shrouds to prevent airflow on the backside of the valves into the combustion chamber. In this case, we can change the ports with different diameters to investigate the air flow and swirl motion. In addition, one of the ports is blocked to determine the effect of the swirl generation as the one intake port. So the results with the single port and a shrouded valve show the higher swirl generation to improve the efficiency of an engine through increasing the combustion rate of the air-fuel mixture.

In the DI engine, two experimental simulations can be achieved to increase the air-fuel mixture: one way is designing the combustion chamber structure for increasing the air-fuel mixture. Another way is designing the intake systems by blocking one of the ports or using the shrouded valve to impact a swirling motion into the combustion chamber. The swirl ratio and the fluid motion are important effect on air-fuel mixing, combustion, heat transfer and exhaust emissions.

\section{CFD Modeling of ICE Procession}

The experimental simulation works in cylinder flows have been conducted to measure velocity fields by using the hot wire anemometry or lased Doppler velocimetry (LDV) [1]. It is a really hard task to perform it because the measurements of in-cylinder flows in the reciprocating engine are characterized by highly complex three-dimensionality turbulence and unsteadiness [1]. Therefore, the numerical approach could be changed, use the CFD model to develop for the in-cylinder flow predictions. The computer codes are utilized to solve the Navier-Stokes equations to produce detailed descriptions of the mean velocity and the turbulence velocity fields. While showing ICE case, the CFD model should solve the specific problems about the air-fuel mixture into the combustion chamber turbulence flow, high Reynolds number, compressible flow and the air-fuel mixture through the geometry model.

\section{Navier-Stokes Equations}

Fluid dynamics deals with the motion of liquids and gases. Which when studied macroscopically, appear to be continuous in structure. All the variables are considered to be continuous functions of the spatial coordinates and time. The Navier-Stokes equations are a set of nonlinear partial differential equations that describe the flow of fluids. The Navier-equations for irrotational flow are shown below.

$$
\begin{aligned}
& \frac{\partial \rho}{\partial t}+\nabla \cdot(\rho \mathrm{u})=0 \quad \text { Continuity Equation } \\
& \frac{\partial u}{\partial t}+(\mathrm{u} \cdot \nabla) \mathrm{u}=-\frac{1}{\rho} \nabla \mathrm{p}+\mathrm{F}+\frac{\mu}{\rho} \nabla^{2} \mathrm{u} \\
& \text { Equations of Motion } \\
& \rho\left(\frac{\partial}{\partial x}+\mathrm{u} \cdot \nabla \varepsilon\right)-\nabla \cdot\left(\mathrm{K}_{\mathrm{H}} \nabla \mathrm{T}\right)+\mathrm{p} \nabla \cdot \mathrm{u}=0
\end{aligned}
$$

*Corresponding author: Muk Choa H, Division of Mechanical and Automotive Engineering, Kongju National University 275, Budae-dong, Cheonan-si, Chungcheongnam-Do 331-717, South Korea, Tel: +82 41-850-8114; E-mail: hmcho@kongju.ac.kr

Received May 27, 2016; Accepted June 27, 2016; Published June 30, 2016

Citation: Xu CC, Choa MH (2016) A Computational Fluid Dynamics Study of the Swirl Generation Analysis in Four-stroke Direct Injection Engine. J Appl Mech Eng 5: 221. doi:10.4172/2168-873.1000221

Copyright: (c) 2016 Adarsh PM, et al. This is an open-access article distributed under the terms of the Creative Commons Attribution License, which permits unrestricted use, distribution, and reproduction in any medium, provided the original author and source are credited. 


\section{Conservation of Energy}

Where $\mathrm{u}=$ velocity vector field, $\varepsilon=$ thermodynamic internal energy, $\mathrm{p}=$ pressure, $\mathrm{T}=$ temperature, $\rho=$ density, $\mu=$ viscosity, $\mathrm{K}_{\mathrm{H}}=$ heat conduction coefficient, $\mathrm{F}=$ external force per unit mass.

$$
\begin{aligned}
& \nabla=\frac{\partial}{\partial x} \mathrm{i}+\frac{\partial}{\partial y} \mathrm{j}+\frac{\partial}{\partial z} \mathrm{k} \\
& \nabla^{2}=\frac{\partial^{2}}{\partial x^{2}}+\frac{\partial^{2}}{\partial y^{2}}+\frac{\partial^{2}}{\partial z^{2}}
\end{aligned}
$$

In this study, the CFD code of the capability of moving mesh and boundary algorithms to investigate the effect of the piston crown shape to the fluid flow field that use the valves and piston movement capability. The first to find the better piston crown shape to measure when the same composition of air structure for fuel mixing preparation that occurred inside engine cylinder. Therefore, this study is that the fluid flow with two different combustion chambers influence in air-flow mixing preparation and generation of turbulence for great impact on engine performance. During intake and compression stroke, numerical calculation is performed to obtain the optimum parameters for engine, which influences to accomplish the better air and fuel mixing for the rapid combustion process for studying the effect of the combustion chamber shape to the fluid flow field.

The numerical computation was using the analysis of intake and compression stroke for the swirl generation of air-fuel mixture into the chamber with two different piston crowns, with its boundary conditions. This engine speed considered in this work is $2000 \mathrm{rpm}$ with the fixed valve timing and lift. The two parameters for the fluid flow characteristics acquired from the simulation will be taken into account to verify the same composition of air structure for mixture preparation so that the better air-fuel mixture when compression stroke combustion process can be achieved [1]. In particular, in the experiment process, the difference test observed for the two different piston bowl shapes can be drawn out with the parameters conformation of fluid flow characteristics during intake and compression stroke [2]. From the simulation experiment, we can observe the piston crown shape impact the air-fuel swirl combustion processes to improvement of the piston crown shape for obtaining the better engine performance and exhaust emissions. The CFD simulations use the moving mesh-boundary algorithm that to use the different mesh and boundary geometries for different crank angle in each step of engine cycle for getting different air-fuel swirl. In order to perform the better CFD simulations for an internal combustion process, the analysis and calculation should be carried out by using the unsteady calculation, moving meshes and boundaries, high compressible Reynolds number, high fluid dynamics characteristics, momentum, heat and mass transfer and the air-fuel mixture through complex geometries model and chemical-thermal dependent as well [1]. In addition, the calculation of the flow field in different combustion chambers was compared with Laser Doppler Velocimetry measurements (LDV).

The CFD code developed to simulate three-dimensional curvilinear domains using the finite volume method in a collocated grid. It employs the standard $\mathrm{k}-\varepsilon$ turbulence model in the vector notion with some slight modifications to introduce the compressibility of a fluid. It solves the follows transfer equations for describing mass, momentum and energy [3].

$$
\frac{\partial(\rho \phi)}{\partial t}+\nabla \cdot(\rho \phi \vec{u})=\nabla \cdot\left(\Gamma_{\phi}(\phi)\right)+\mathrm{S}_{\phi}
$$

Where, $\vec{u}$ is the velocity vector with components $\mathrm{u}, v$ and $w, \rho$ the

\begin{tabular}{|c|c|c|}
\hline Variable & $\Gamma_{\phi}$ & $\mathbf{S}_{\phi}$ \\
\hline k & $\mu_{\text {eff }} / \sigma_{\mathrm{k}}$ & $G_{K}-\rho \varepsilon$ \\
\hline$\varepsilon$ & $\mu_{\text {eff }} / \sigma_{\varepsilon}$ & 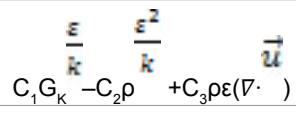 \\
\hline
\end{tabular}

\begin{tabular}{|c|c|c|}
\hline $\begin{array}{c}\text { Generalized flow field } \\
\text { variable }(\phi)\end{array}$ & Equation & $\Gamma_{\phi}$ \\
\hline I & Continuity & 0 \\
\hline u & u-Momentum & $\mu_{\text {eff }}$ \\
\hline v & v-Momentum & $\mu_{\text {eff }}$ \\
\hline w & w-Momentum & $\mu_{\text {eff }}$ \\
\hline h & Enthalpy & $\mu_{\text {eff }} / \mu_{\mathrm{h}}$ \\
\hline k & Turbulent kinetic energy & $\mu_{\text {eff }} / \mu_{\mathrm{k}}$ \\
\hline$\varepsilon$ & Dissipation of turbulent kinetic energy & $\mu_{\text {eff }} / \mu_{\varepsilon}$ \\
\hline
\end{tabular}

Table 1: Variables representing the generalized variable $\phi$ in Equation (6) [3].

Table 2: Source terms of the turbulence variables [3]

density, $\phi$ the generalized transport property and $S_{\phi}$ the source term. In Table 1, all the variables corresponding to the general transport property are shown [3].

For the turbulence model, specifically the source terms of the turbulence kinetic energy and its dissipation can be seen in Table 2, where $G_{k}$ is the turbulent kinetic energy production rate [3].

The turbulent viscosity is calculated from the following Eq. (7), and the effective viscosity used in the calculations is the sum of the turbulent and laminar viscosity. Also, all the constants used in the implementation of the $\mathrm{k}-\varepsilon$ turbulence model and the enthalpy equation are shown in Table 3 [3].

$$
\mu_{\mathrm{t}}=\frac{\rho k^{2} C_{\mu}}{\varepsilon}, \mu_{\text {eff }}=\mu_{1}+\mu_{2}
$$

\section{Engine Geometry Analysis}

The engine model studied is a typical single-cylinder of a CNG-DI engine with two intake and exhaust valves as shown Figure 1 and with two pistons shapes structure shown Figure 2. From above mentioned, two piston crowns were considered to investigate the behavior of the swirl and tumble flows occurred inside cylinder in order to obtain the better piston shape for the combustion process in the engine. Piston shapes shown in Figure 2, two piston shapes are typical of the real engine geometry model that affect the air-fuel mixture swirl for obtaining the higher swirl ratio as well as the optimum combustion process in the DI engine. Piston A has a bowl at the center of its piston crown while piston $B$ has the deeper bowl volume than piston $A$, and piston $B$ bowl is different from piston $\mathrm{A}$ that the bowl is not at the center of its piston crown [1].

The compare of the bowls on piston crown surface when air-fuel flows into the combustion chamber to generate swirl, which according to the piston shapes to form the air-fuel swirl of influence to obtain the better piston shape for combustion process in the engine, and operation the piston boundary conditions use the CFD model analysis during the intake and compression process.

During the compression stroke, the swirl generated by the annular jet flows during the previous intake stroke decay quite quickly and remains seem to be distributed homogeneously along the engine cylinder. And the air-fuel with quite quickly velocity to make air-fuel mixture full mix whether or not depending on the piston crown shape, 


\begin{tabular}{|c|c|c|c|c|c|c|c|}
\hline Constant & $\mathrm{C}_{1}$ & $\mathrm{C}_{2}$ & $\mathrm{C}_{3}$ & $\mathrm{c}_{\mu}$ & $\mathrm{C}_{\mathrm{h}}$ & $\mathrm{C}_{\mathrm{k}}$ & $\mathrm{C}_{\varepsilon}$ \\
\hline Value & 1.44 & 1.92 & -0.373 & 0.09 & 1.0 & 1.0 & 1.3 \\
\hline
\end{tabular}

Table 3: Constants used in the $k-\varepsilon$ turbulence model and the enthalpy equation [3].

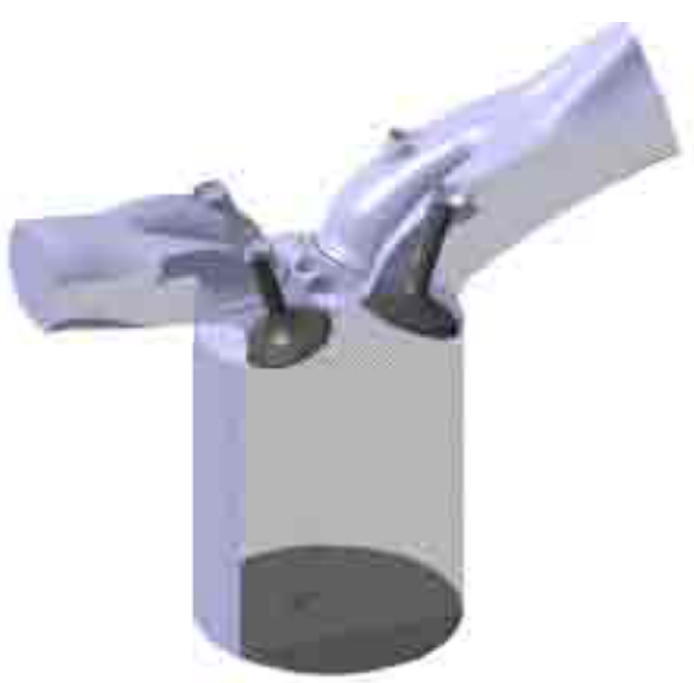

Figure 1: A schematic view of typical engine model with piston crown A [1]

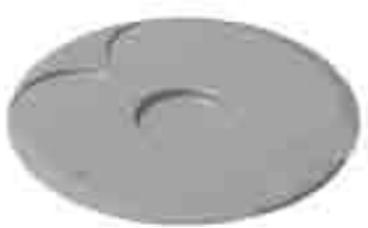

Piston A

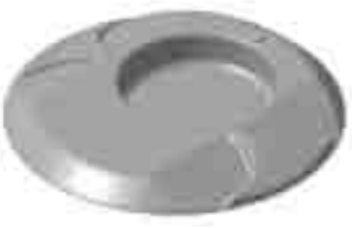

Piston B
Figure 2: Geometry of the combustion chamber [1].

when the combustion chamber shape of an ICE is affect to the velocity field close to the piston top surface during the latter of the compression stroke when the air-fuel injection start and the spark plug ready to burn the air-fuel mixture start end of the compression process. In the compression process, combustion chamber with the different of the piston crown bowl structure that for the purpose of comparing swirl ratio in the combustion chamber.

The experiment analysis obtains variations of swirl ratio for two pistons are calculated and display in Figure 3. As can be seen from the graph, the swirl is generated before the start of the intake stroke in the cylinder. Because air-fuel before into the cylinder start to become mixture and inside the cylinder due to the piston crown shape air-fuel with quite quickly velocity generate swirl by annular jet to full mix, as shown in Figure 3. The maximum is achieved near around $140^{\circ}$ after TDC, where the piston reaches the maximum speed and the valve opening is in maximum distance. And after that, the air-fuel velocity into the cylinder decreases and swirl will fail slowly during the intake stroke. In the first part of the compression stroke, swirl velocity due to the friction at the cylinder wall the trend continues to fail slowly. Therefore, follow this graph the swirl is developed as the flow accelerates in preserving its angular momentum within the smaller diameter

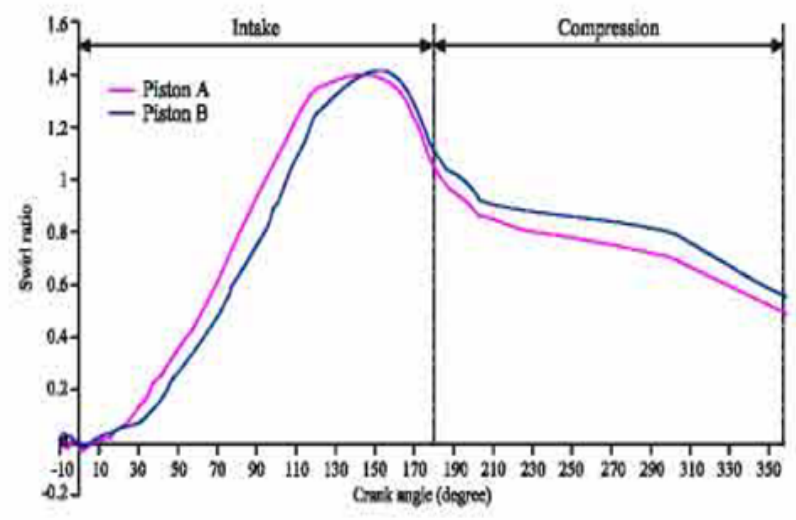

Figure 3: Calculate the swirl ratio versus crank angle [1]

piston bowl when approaching TDC [3]. During the compression stroke, swirl is necessary needed to generate a complex flow field for the purpose of enhancing air-fuel mixture during fuel injection process. From the analysis, the piston A due to smaller diameter crown shape is able to generate higher swirl ratio than piston $\mathrm{B}$ with small range differences during intake and compression strokes. But because of the fraction within the cylinder wall and its intake air flows influence by combustion chamber head shape.

\section{Swirl Ratio Analysis Use and the CFD Code of KIVA-3V}

This case is conducted to investigate the effect of the intake system design on swirl ratio use the computer code KIVA-3V in a DI engine [4]. The KIVA-3V code is used to study the effect of the one or two ports and intake position with shrouded valves for the swirl ratio.

The engine studied in this case is a single-cylinder direct-injection Diesel engine with typical two direct intake ports whose outlet is tangential to the wall of the cylinder, as shown in Figure 4 [4].

The simulations were performed through the intake and compression strokes. And the mesh had about 150,000 cells [4]. Pressure inflow boundaries were imposed at the open ends of the intake runners. For this cases, when shrouded valves were used on the backside of the valves prevent the air-fuel into the cylinder through backside position of the valve is shown Figure 5. Conventional engine, air can flow around all sides with un-shrouded valve through intake port into the cylinder in all directions. In order to improve the air-fuel swirl ratio in the cylinder that in the intake and compression strokes processes, therefore a shrouded valve is added to the backside of the valve, air flow will only flow in one direction of the valve into the cylinder is shown in Figure 6 [4].

The values of air-fuel swirl ratio for the different crank angles were calculated and plotted in Figure 7 [4] shown that this case with one port and a shrouded valve obtained the highest air-fuel swirl ratio. The case with one port intake the air-fuel into the cylinder is stronger than two or more ports intake through the pipe. Similarly the shrouded valve in the backside of the valve prevents the flow through the backside of the valve into cylinder, and makes the flow through the front side into cylinder strongly for enhancing the swirl motion. So the experiment simulation results shown this case with one port or a shrouded valve can generate higher air-fuel swirl ratio than two or more ports or un-shrouded valve. Therefore, with intake and compression strokes, the shrouded valve can 

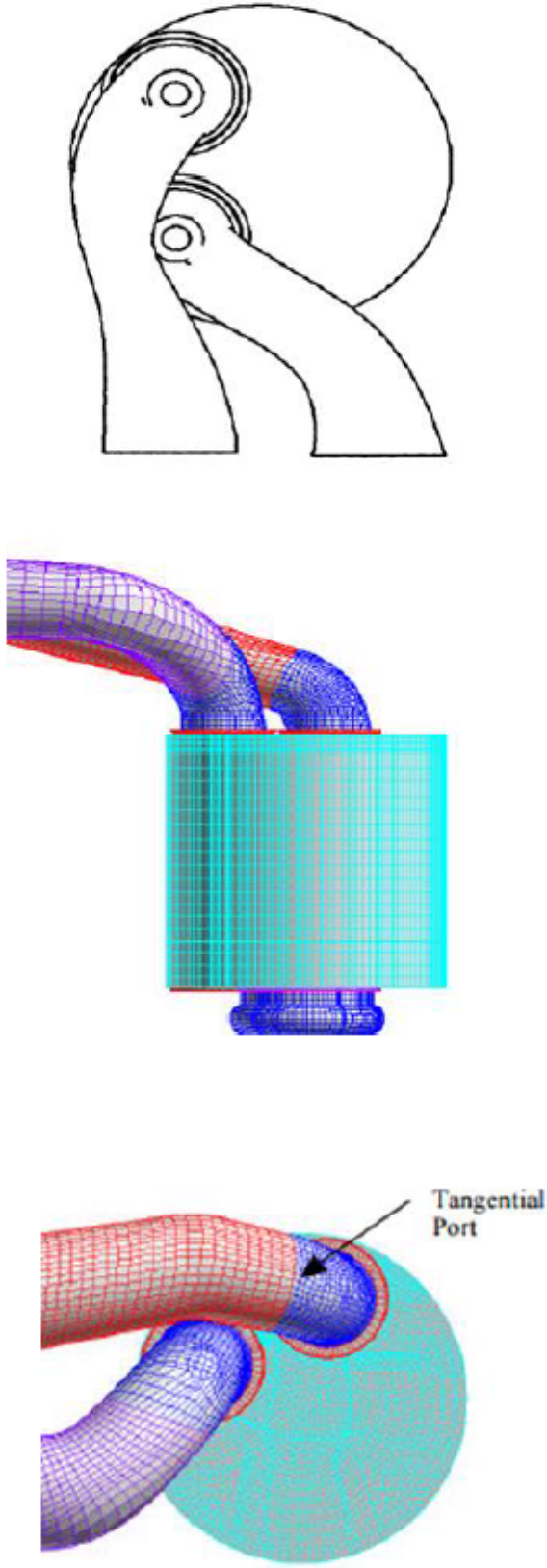

Figure 4: Schematic of engine and computational mesh $[2,4]$.

improve and enhance the swirl ratio when the air-fuel through the valve into the cylinder chamber in the CNG-DI engine [4].

For this case, the effect of one or two ports on swirl ratio can be considered. This method is similarity to added shroud valve on the backside of valve that block one port to determine if a single port would generate a higher swirl ratio than two ports. Then similarly this air-fuel swirl ratio can be shown in Figure 7 [4].

\section{Other Methods for Enhancing Swirl Ratio}

From above methods, other methods can enhance swirl ratio for intake

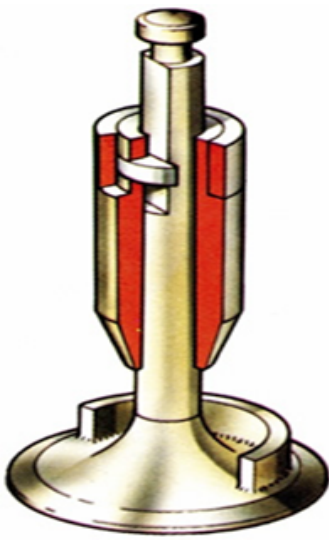

Figure 5: conventional valve with a shroud.

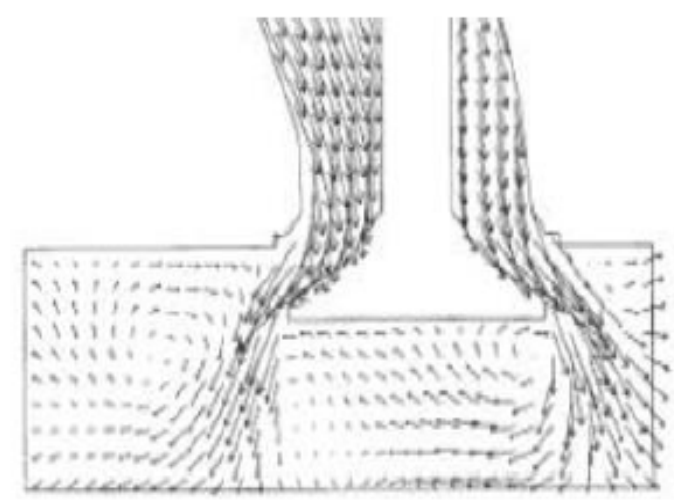

(a)

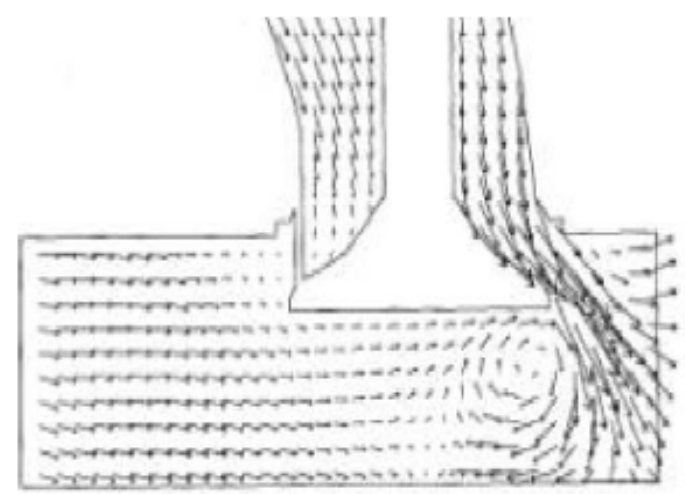

(b)

Figure 6: Show the flow through (a) shroud valve and (b) un-shroud valve [4].

and compression strokes in the engine. From above mentioned, we can change port number to enhance the swirl ratio. The effect of port diameter on swirl ratio can be considered [4], reduce the port diameter for enhancing the flow velocity and air-fuel mixture into the combustion chamber. The narrow port obtains the better swirl ratio than width port, because as the 
Citation: Xu CC, Choa MH (2016) A Computational Fluid Dynamics Study of the Swirl Generation Analysis in Four-stroke Direct Injection Engine. J Appl Mech Eng 5: 221. doi:10.4172/2168-873.1000221

Page 5 of 5

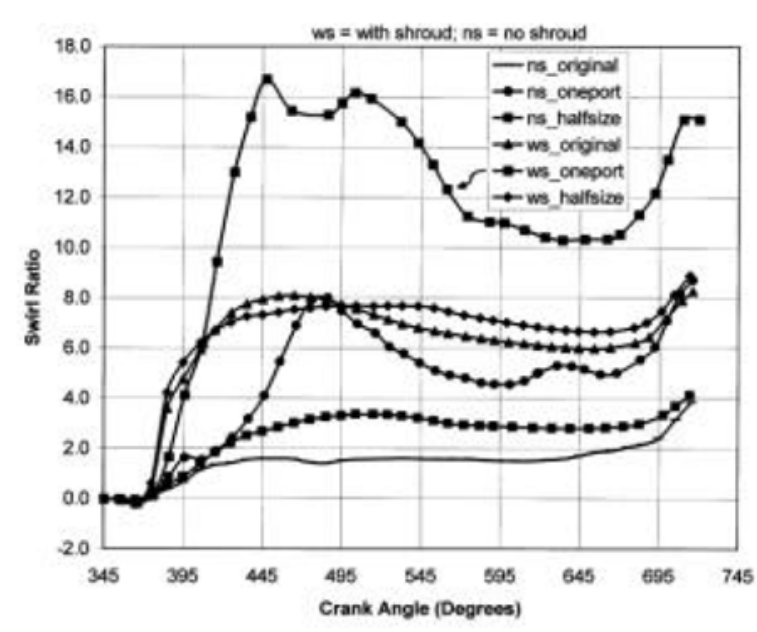

Figure 7: Swirl ratio versus crank angle [4].

port is narrow, the flow pressure is smaller than combustion chamber, so air-fuel is inhaled rapidly due to the pressure difference. Other methods involve change the injection timing [5-8] and variable valve timing and dual-fuel inside the cylinder [7] and late second injection variations [9-11] can affect the air-fuel mixture.

\section{Conclusions}

The Computational fluid dynamic investigation is carried out to study the effect of the piston crown structure to the fluid flow field in inside the combustion chamber, and investigation the intake system and compression strokes to enhance swirl ratio to solve CFD code.

(1) This paper is carried out for two piston crown shapes to evaluate the effect of different combustion chamber shape to the fluid flow field for the air-fuel mixture before fuel injection begins, and to obtain the better piston crown shape for swirl ratio for the combustion chamber in the DI engine.

(2) For the intake system design can be considered in this case, and investigated through the CFD code of KIVA-3V model. Increase the burn rate of the air-fuel mixture for the efficiency of the engine that change the port number and add shroud valve for considering on the swirl ratio. The results can be derived that use shrouded in the cylinder and get the higher swirl ratios than with un-shrouded valves.

\section{References}

1. Kurniawan WH, Abdullah S, Shamsudeen A (2007) A Computational fluid dynamics study of cold-flow analysis for mixture preparation in a motored fourstroke direct injection engine. J Applied Sciences 7: 2710-2724.

2. Payri F, Benajes J, Margot X, Gil A (2004) CFD modeling of the in-cylinder flow in direct-injection diesel engines. Computers \& Fluids 33: 995-1021.

3. Rakopoulos CD, Kosmadakis GM, Pariotis EG (2010) Investigation of piston bowl geometry and speed effects in a motored HSDI diesel engine using a CFD against a quasi-dimensional model. Energy Conversion and Management 51: 470-484.

4. Ramadan B (2003) A study of swirl generation in DI engines using KIVA-3V [J] Kettering University.

5. Jayadhankara B, Ganesan V (2010) Effect of fuel injection timing and intake pressure on the performance of a DI diesel engine - A parametric study using CFD. Energy Conversion and Management 51: 1835-1848.

6. kailas PP, Hemant WK, Vijayenra Maharu P, Anil HK (2014) Study of combustion in DI diesel engine for different compression ratios using experimental and CFD approach. Int J Research in Engineering and Technology (IJRET) 3: 2321-7308.

7. Hussain SM, Sudheer Prem Kumar B, Vijaya Kumar Reddy K (2012) CFD analysis of combustion and emissions to study the effect of compression ratio and biogas substitution in a diesel engine with experimental verification. Int $J$ Engineering Science and Technology (IJEST) 4: 0975-5462.

8. Vijayendra Maharu P, Agrawal A (2014) Optimization of time step and CFD study of combustion in DI diesel engine. IJRET Int $\mathrm{J}$ Research in Engineering and Technology 3: 2319-1163.

9. Coskun G, Soyhan HS, Demir U, Turkcan A, Ozsezen AN et al. (2014) Influences of second injection variations on combustion and emissions of an $\mathrm{HCCl}-\mathrm{DI}$ engine: Experiments and CFD modelling. Fuel 136: 287-294.

10. Holkar R, Sule-Patil YN, Pise SM, Godase YA, Jagadale VS (2015) Numerica simulation of steady flow through engine intake system using CFD. IOSR J Mechanical and Civil Engineering (ISOR-JMCE) 12: 30-45.

11. Abdul Gafoor CP, Gupta R (2015) Numerical investigation of piston bowl geometry and swirl ratio on emission from diesel engines. Energy Conversion and Management 101: 541-551. 